
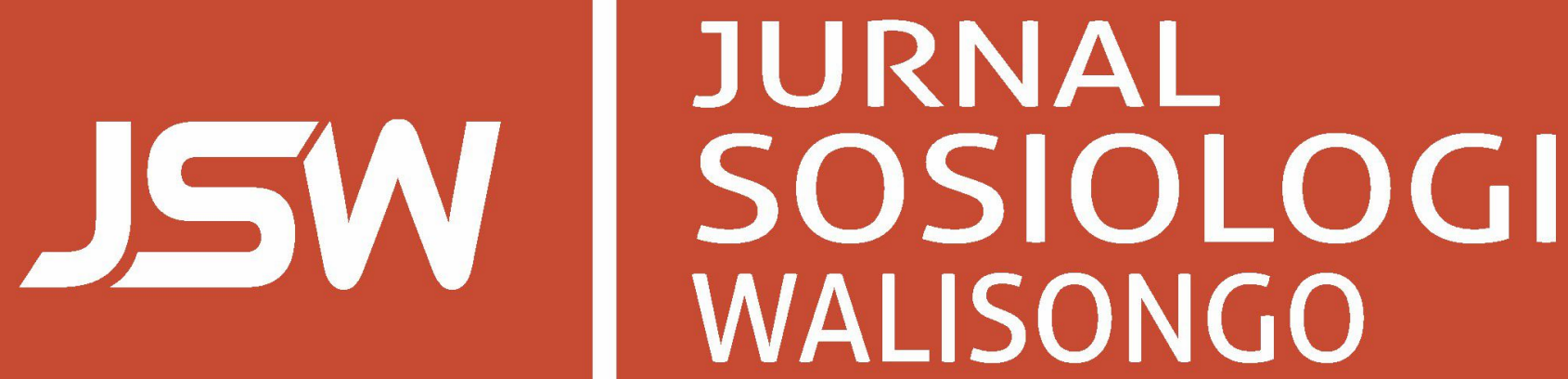

Studi Etnoekologi tentang Nelayan dan Jaring Cantrang

di Kabupaten Rembang

Hesti Rofika Sari, Nugroho Trisnu Brata

Perlawanan Visual Perempuan dalam Poster

Misbah Zulfa Elizabeth

Kearifan Budaya Lokal sebagai Benteng Munculnya Konflik Agama Muhammad Alfan Sidik

Ulama Pasca Sunan Gunung Jati: Jaringan Intelektual Islam Cirebon Abad ke-16 sampai dengan Abad ke-18

Didin Nurul Rosidin

Membangun Harmoni Sosial: Kajian Sosiologi Agama tentang Kearifan Lokal sebagai Modal Dasar Harmoni Sosial David Samiyono

Analisis Komparatif atas Hasil Tracer Study Program Studi Hubungan Internasional dan Administrasi Negara Muhyar Fanani, Akhriyadi Sofian, Kaisar Atmaja, Endang Supriadi

Melihat Indonesia dari Jendela Papua: Kebinekaan dalam Rajutan Budaya Melanesia Akhmad Kadir 

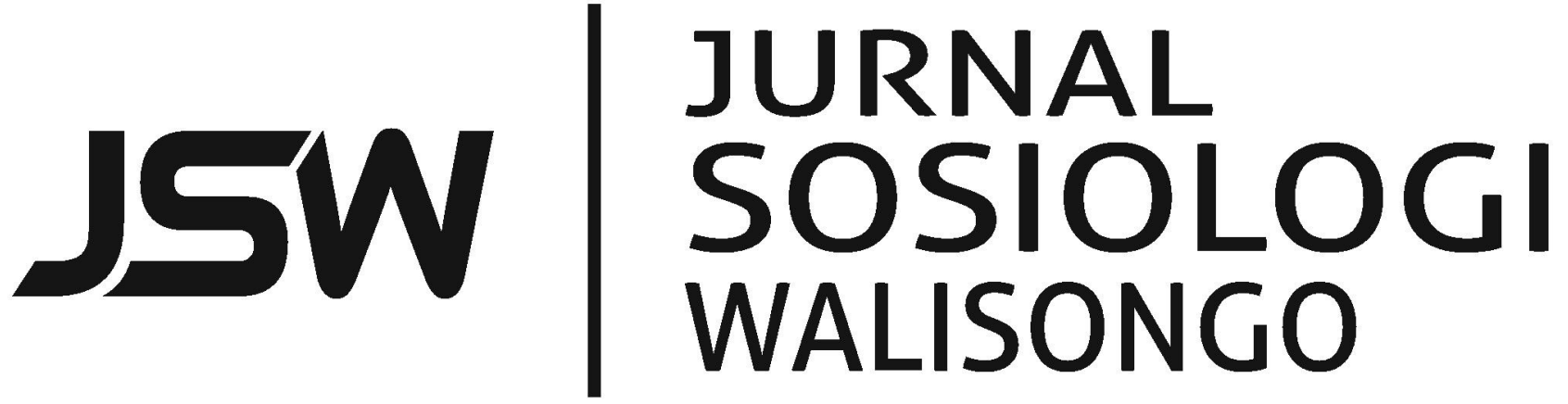

JSW: Jurnal Sosiologi Walisongo - ISSN 2503-3166 (print) ISSN 2503-3182 (online) is a critical, reflective, and transformative academic media that is published by Laboratorium Sosiologi, Fakultas IImu Sosial dan IImu Politik, Universitas Islam Negeri Walisongo Semarang, in the effort for developing the discipline of Sociology having the perspective of unity of sciences. Article is based on research in all division of sociology like sociology of religion, sociology of politic, sociology of law, sociology of development, urban/rural sociology, democracy, social ethic, anthropology, community development, social philosophy, gender, and social welfare.

\section{Editor in Chief}

Misbah Zulfa Elizabeth, Universitas Islam Negeri Walisongo, Semarang

\section{Expert Editor}

Abu Rokhmad, Universitas Islam Negeri Walisongo, Semarang

Muhyar Fanani, Universitas Islam Negeri Walisongo, Semarang

Thohir Yuli Kusmanto, Universitas Islam Negeri Walisongo, Semarang

\section{Editor}

Kaisar Atmaja, Universitas Islam Negeri Walisongo, Semarang

Akhriyadi Sofian, Universitas Islam Negeri Walisongo, Semarang

Nur Hasyim, Universitas Islam Negeri Walisongo, Semarang

\section{Layout Editor}

Helmi Suyanto, Universitas Islam Negeri Walisongo, Semarang

Ulul Azmi, Universitas Islam Negeri Walisongo, Semarang

\section{Publisher}

LABORATORIUM SOSIOLOGI

Fakultas IImu Sosial dan IImu Politik

Universitas Islam Negeri Walisongo

Semarang - Indonesia

\section{Address}

Gedung A - Fakultas IImu Sosial dan IImu Politik (FISIP)

Universitas Islam Negeri Walisongo, Semarang - Indonesia

Jl. Prof. Dr. HAMKA, Km. 2 Tambakaji Ngaliyan Semarang 50185

Phone +62.24 - 76435986

e-mail:jurnal.sosiologi@walisongo.ac.id 


\section{Table of Contents}

Studi Etnoekologi tentang Nelayan dan Jaring Cantrang di Kabupaten Rembang

Hesti Rofika Sari, Nugroho Trisnu Brata (Universitas Negeri

Semarang)

$135-146$

Perlawanan Visual Perempuan dalam Poster

Misbah Zulfa Elizabeth (Universitas Islam Negeri Walisongo,

Semarang)

$147-160$

Kearifan Budaya Lokal sebagai Benteng Munculnya

Konflik Agama

Muhammad Alfan Sidik (STAI Natuna)

$161-176$

Ulama Pasca Sunan Gunung Jati: Jaringan Intelektual Islam

Cirebon Abad ke-16 sampai dengan Abad ke-18

Didin Nurul Rosidin (Institut Agama Islam Negeri Syekh Nurjati,

Cirebon)

$177-194$

Membangun Harmoni Sosial: Kajian Sosiologi Agama tentang

Kearifan Lokal sebagai Modal Dasar Harmoni Sosial

David Samiyono (UKSW, Salatiga)

$195-206$

Analisis Komparatif atas Hasil Tracer Study Program Studi

Hubungan Internasional dan Administrasi Negara

Muhyar Fanani, Akhriyadi Sofian, Kaisar Atmaja, Endang Supriadi

(Universitas Islam Negeri Walisongo, Semarang)

$207-224$

Melihat Indonesia dari Jendela Papua: Kebinekaan dalam

Rajutan Budaya Melanesia

Akhmad Kadir (Universitas Cendrawasih, Jayapura)

$225-246$

Author Guidelines

JSW: Jurnal Sosiologi Walisongo - Vol 1, No 2 (2017) 



\title{
Perlawanan Visual Perempuan dalam Poster
}

\author{
Misbah Zulfa Elizabeth \\ Universitas Islam Negeri Walisongo, Semarang \\ (e-mail: zulfa_elizabeth@walisongo.ac.id)
}

\begin{abstract}
Visual expression is something un-denayable in social life because the viasuality is the expression of the social life. This article has the purpose to explore how visual expression of women resistance toward gender inequality. Applying qualitative research with the method of documentation study this article in detail analyses the interpretation of religious text as the source of inequality and gender reality in social context. It is revealed that visual expression of the poster suggesting to treat men and women respectfully is the resistance toward religious text interpretation which is inequally treat men and women
\end{abstract}

Realitas visual merupakan realitas yang tidak dapat diabaikan dalam kehidupan karena visualitas juga merupakan gambaran dari realitas kehidupan itu sendiri. Artikel ini bertujuan untuk mengkaji bagaimana ekspresi visual perlawanan perempuan terhadap ketidakadilan gender. Dengan menggunakan penelitian kualitatif dan metode studi dokumen, artikel ini secara detail menganalisis interpretasi teks agama sebagai sumber ketidakadilan gender serta realitas gender dalam konteks masyarakat. Terungkap dari kajian ini bahwa ekspresi visual poster yang meneguhkan agar laki-laki dan perempuan saling menghormati, merupakan resistensi terhadap interpretasi teks yang memperlakukan laki-laki dan perempuan secara tidak adil.

Keywords: inequality; interpretation of religious; poster; resistance; gender

\section{Pengantar}

Kehidupan masyarakat saat ini tidak dapat dilepaskan dari berbagai realitas gambaran visual yang semakin canggih (sophisticated) saja (Howels 2004). Gam- baran visual adalah gambaran atau bendabenda lainnya, baik diam maupun bergerak, yang dibuat oleh manusia untuk dipandang atau ditonton (to be looked at) (Walker, John A. dan Sarah Chaplin 1997). Berbagai bentuk gambaran visual missal- 
nya poster, foto, acara televisi, iklan, film, video, gambar digital dan lukisan (Walker A John dan Sarah Chaplin 1997; Howells 2004; Rose 2007). Karena tingkat kelaziman dari realitas visual itu maka hampir dapat dikatakan bahwa di setiap lingkup masyarakat selalu terdapat representasi visual.

Pembicaraan mengenai realitas gambaran visual terkait erat dengan pembicaraan tentang visualitas (visuality). Visualitas dalam kaitan ini merujuk pada cara pandangan (vision) dikonstruksi dengan berbagai cara: bagaimana kita melihat, bagaimana kita mampu, dimungkinkan, dipaksa melihat, dan bagaimana kita melihat yang tampak di mata atau yang ada di baliknya (the seeing and the unseeing therein) (Rose 2007). Istilah yang seringkali dipandang hampir sama dengan istilah visualitas adalah scopic regime. Kedua istilah ini mengandung makna bahwa apa yang dilihat dan bagaimana benda dilihat dikonstruksi secara budaya (Howells 2004). Dalam pengertian semacam ini sebenarnya media visual merupakan kajian budaya. Dengan kenyataan inilah kajian dalam bidang visualitas menjadi demikian berkembang dalam empat dekade terakhir abad ini (Rose 2007).

Adapun perkembangan kajian ini utamanya, sebagaimana dinyatakan oleh Gillian Rose (2007) terkait erat dengan perkembangan ilmu sosial budaya pada dekade tahun 70-an. Dalam dekade itu ilmu sosial dan budaya dinyatakan mengalami perubahan yang signifikan dalam pemahamannya terhadap kehidupan sosial. Perubahan ini seringkali disebut sebagai "cultural turn". "Culture” (budaya) dalam konteks ini menjadi persoalan penting yang dengan budaya itu para ahli ilmu sosial memahami berbagai proses sosial, identitas sosial, dan perubahan sosial serta konflik. Kondisi lain yang menyertai perubahan pada dekade itu adalah munculnya orientasi pada "the other' science" seperti kajian gender dan seni. Namun demikian kenyataan itu tidak sendiri karena realitas lain juga ikut mempengaruhi, seperti perkembangan industri media yang mengakibatkan konsumsi massa (Walker A John dan Sarah Chaplin, 1997; Howells, 2004; Rose, 2007). Perkembangan yang diakibatkan oleh perkembangan industri media itu memang dapat dipahami dalam konteks fenomena globalisasi. (Appadurai 2005; Featherston 2001; Hine 2000).

Sebagai media komunikasi dan transmisi informasi, media visual dapat dibandingkan dengan media tulisan, dan tampak bahwa keduanya sama-sama dapat "dibaca" dengan kekuatan yang sama dengan media tulis. Media visual dapat digunakan untuk menemukan bagaimana dan apa makna yang dikandung dalam media visual itu. Dengan strategi analisis yang tepat media visual 
dapat ditangkap rahasia yang dikandungnya (Howells 2004). Media visual dapat merepresentasi dan memproduksi realitas (Walter Benjamin dalam Regev 2007). Jadi media visual tidak semata sebagai assesoris, yang seolah tidak menjadi masalah jika tidak dimuat, namun dapat berbicara sendiri atau setidaknya saling melengkapi media tulis.

Namun demikian, potensi media visual yang demikian bermakna baru diketahui dan dimanfaatkan oleh segelintir ilmuwan sosial budaya. Beberapa ilmuwan yang telah menggunakan media visual dalam karya mereka misalnya, Budi Susanto, S. J. (1993; 2008), Rudollf Mrazek (2003), P. M. Laksono (2004). Ketiga ilmuwan ini telah memanfaatkan media visual bersama dengan media tulis untuk membicarakan fakta secara mendalam. Ketika paparan telah memberikan gambaran mengenai realitas, ekspresi visual semakin menguatkan paparan mengenai realitas tersebut, sehingga pembaca memperoleh gambaran yang semakin jelas

Budi Susanto, S. J. (1993) dalam Peristiwa Yogya 1992: Siasat Politik Massa Rakyat Kota membicarakan tentang fenomena pemilihan umum di Yogya, yang dengan interpretasi yang "baru" mampu memberikan pemahaman akan adanya realitas yang lain dibandingkan dengan deskripsi yang mainstream. Rudolf Mrazek (2003), seorang sejarawan, dalam Engineers of Happy Land menulis realitas sejarah secara berbeda. Meskipun mengambil judul yang bernuansa teknologis, namun Mrazek menggunakan teknologi sebagai metode, dan bukan sebagai pokok bahasan. Dengan metode itu, dengan menggunakan bahan-bahan visual Mrazek mengungkap realitas budaya, identitas, dan bangsa Indonesia pada masa akhir penjajahan dengan paparan yang tidak terduga dan kaya serta dalam. P. M. Laksono (2004) melalui "Mediasi-mediasi Visual Sebelum dan Sesudah Reformasi di Indonesia: Sebuah Pencarian Keadilan Sosial" dalam Keadilan Sosial: Upaya Mencari Makna Kesejahteraan Bersama di Indonesia memanfaatkan gambar-gambar mural di berbagai tempat di Yogyakarta untuk mengekspresikan level-level identitas dan proses sosial yang dilami oleh anggota komunitas Yogyakarta.

Adanya diskursus sebagaimana dipaparkan di atas, menarik untuk melakukan kajian terhadap gambar visual yang berkait dengan ketidakadilan gender. Yang menjadi fokus dari tulisan ini bagaimana ekspresi visual perlawanan perempuan terhadap ketidakadilan gender. Ekspresi visual yang dimaksudkan di dalam kajian ini adalah poster yang diterbitkan oleh beberapa lembaga, yang muatannya adalah untuk memperjuangkan keadilan dan kesetaraan gender. Adapun alasan pemanfaatan poster di dalam kajian ini, karena poster memuat gambar yang tampak. Gambar di dalam poster 
berpadu dengan dengan bahasa tulis secara dialektik (Laksono, 2004) untuk menunjukkan fenomena perlawanan. Fenomena perlawanan dapat dengan tegas ditangkap karena poster merupakan salah satu bentuk media visual.

Sebagai gambar visual, poster memiliki dua unsur, yaitu studium and punctum. Studium merujuk pada interpretasi budaya, linguistik, dan politik dari sebuah karya foto sementara punctum menunjuk pada detail yang menyentuh, yang menegaskan hubungan langsung dengan obyek atau person di dalamnya (Barthes 1981). Apa yang tampak secara langsung adalah punctum, karena punctum merupakan interaksi pandangan audience dengan gambar visual yang tersaji. Sementara itu studium merupakan pemaknaan dari realitas yang terekspresi di dalam poster. Secara metodologis studium muncul sebagai hasil penjelasan interpretif atas studium yang tersaji. Dalam konteks studium inilah konteks sosial budaya dapat terwadahi penjelasannya dalam sebuah sajian teks poster

Pembicaraan mengenai perlawanan mengarahkan pada kajian para ahli poststrukturalis seperti James Scott (2004). Yang dimaksudkan dengan perlawanan di sini merujuk pada kata resistance, yang maknanya adalah perlawanan yang dilakukan secara diam-diam dan sembunyisembunyi dari kelompok atau komunitas yang secara struktural dan kultural tidak memiliki kekuatan atau subordinated terhadap komu-nitas yang kuat dan superior. Thomas, et al. (2005) menjelaskan bahwa resistensi itu pada umumnya dipahami sebagai perlawanan terhadap kekuatan yang memberikan kontrol secara terstruktur dan hubungan yang ditunjukkan antara kontrol dengan perlawanan itu bersifat dyadic (control-resistance dyadic relationship). Hubungan dyadic adalah hubungan antara dua orang yang melibatkan aspek emosi dan perasaan, sehingga masing-masing pihak saling mempengaruhi satu sama lain (Shinta 2002). Meskipun hubungan dyadic banyak dipahami sebagai hubungan antar individu, namun dalam konteks hubungan komunitas, hubungan dyadic dapat pula terjadi.

Pemaknaan yang diberikan oleh Scott (2004) dalam konteks ini adalah bahwa perlawanan tersebut tidak dinyatakan secara langsung, baik pesan maupun pembawa pesannya. Pesan yang disampaikan dapat berupa simbol-simbol yang untuk memahami simbol-simbol itu dibutuhkan kemampuan tertentu untuk mengetahui kondisi yang sesungguhnya terjadi serta yang sesungguhnya diinginkan oleh kelompok yang terpinggirkan itu (Scott 2004). Dalam konteks seperti inilah poster sebagai sebuah sarana ekspresi juga dapat digunakan sebagai sarana untuk menyampaikan perlawanan. Poster 
memungkinkan ekspresi perlawanan dalam kontinuum yang jauh karena meskipun punctum-nya bersifat verbal, namun studium sangat luas mencakup ekspresi sosial dan budaya, termasuk di dalamnya interpretasi terhadap sebuah teks yang berlaku di dalam sebuah komunitas atau masyarakat.

Perlawanan yang dikaji oleh James Scott (2004) memang spesifik. Maksudnya dapat meliputi perlawanan dalam sisi kehidupan mana pun, sepanjang melibatkan hubungan dyadic, dan merespon pada peristiwa apa pun. Sebagai contoh, relasi atasan-bawahan; orang tua-anak; kakakadik; suami-istri; dan termasuk di dalamnya laki-laki dan perempuan. Perlawanan antar dua pihak yang memiliki hubungan tersebut pun terekspresi secara beragam di berbagai wilayah yang berbeda, serta dimaknai secara berbeda dengan harapanharapan yang berbeda-beda. Hal ini karena setiap bentuk perlawanan memiliki pemaknaan perlawanan tertentu dan pemaknaan itu hanya dapat dipahami dengan cara mencari tahu pihak yang melakukan resistensi itu.

- Bentuk perlawanan memiliki sifat continuum dari tindakan yang bersifat verbal dan non-verbal (Buttler 2004). Ekspresi verbal dapat memiliki rentang dan cakupan dari ekspresi berupa gossip, cerita-cerita rakyat (folktales), lagu-lagu, cerita lucu, dan teater yang diungkapkan tanpa nama dan ambigui, serta perkataan sindiran dan keras. Ini gambaran yang menunjukkan rentang yang meningkat, dari ekspresi yang tidak langsung berupa gossip, cerita rakyat, dan lagu dan maksimal ekspresi yang berupa perkataan keras. Mengacu pada rentang ekspresi verbal di atas, dalam bentuk teks perlawanan dapat memiliki rentang yang panjang pula.

Perlawanan secara diam-diam dilakukan oleh pihak yang lemah, minoritas, dan subordinated karena mereka memandang tidak adanya kesempatan dan peluang bagi mereka untuk menyampaikan pendapat, kehendak dan keinginan mereka (Prasad et al. 1997). Ahli lainnya, yaitu Marshall (1984) menyebutkan bahwa perlawanan diam-diam dilakukan oleh pihak yang subordinated karena pihak subordinated ini membutuhkan perhatian atau perlakuan khusus dalam posisinya sebagai subordinated. Dick dan Cassell (2004) dalam kajiannya juga menyebutkan bahwa perlawanan diam-diam terjadi pada saat kelompok minoritas dan subodinated itu ditekan oleh dominasi dalam struktur organisasional.

Dengan latar belakang sebagaimana dipaparkan di atas, tulisan ini mencoba untuk mengungkap bagaimana ekspresi visual perlawanan perempuan terhadap ketidakadilan gender. Adapun pemanfaatan poster di sini, dengan bahasa tulis, secara dialektik (Laksono 2004), untuk 
menangkap fenomena perlawanan tersebut dengan dasar bahwa poster sebagai salah satu bentuk media visual. Sebagai gambar visual, poster memiliki dua unsur, yaitu studium and punctum. Studium merujuk pada interpretasi budaya, linguistik, dan politik dari sebuah karya foto sementara punctum menunjuk pada detail yang menyentuh, yang menegaskan hubungan langsung dengan obyek atau person di dalamnya (Barthes 1981). Untuk itu tulisan ini akan memfokuskan pembahasannya pada tiga model perlawanan visual dalam konteks kesetaraan gender. Yang pertama adalah perlawanan dalam poster dengan model perlawanan peneguhan perintah untuk memperlakukan perempuan dengan baik; kedua

\section{Perlawanan dengan Peneguhan Perintah untuk Memperlakukan Perempuan dengan Baik}

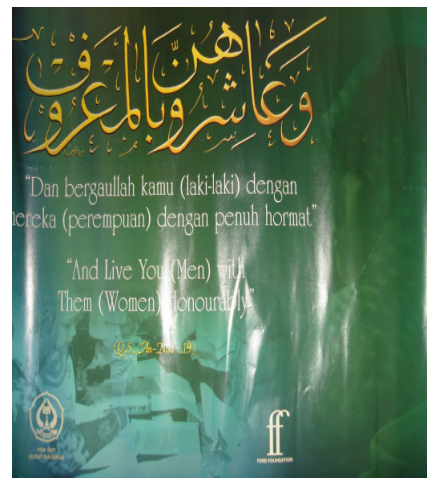

Gambar 1.

Pada Gambar 1 tampak sebuah kaligrafi berbunyi "Wa'asyiru bil ma'ruf" sebuah nukilan ayat di dalam al-Qur'an Surah
Annisaa ayat 19, yang artinya, "Dan pergaulilah kamu (laki-laki) dengan mereka (perempuan) dengan hormat". Ayat ini artinya secara lengkap adalah sebagai berikut:" Wahai orang-orang beriman, tidak halal bagi kalian mewariskan perempuan-perempuan dengan jalan paksa dan janganlah kalian menyulitkan mereka karena ingin mengambil sebagian dari apa yang telah kalian berikan kepada mereka kecuali apabila mereka melakukan perbuatan keji yang nyata. Dan pergaulilah mereka dengan cara yang baik. Jika kalian tidak menyukai mereka maka bisa jadi kalian membenci sesuatu padahal Allah menjadikan kebaikan yang banyak padanya".

Ayat di atas merupakan rujukan dari ajaran Islam yang menghormati perempuan. Dalam ayat itu ditunjukkan bahwa Islam sangat menghargai perempuan dan menjaga hak-hak mereka dengan baik. Salah satu buktinya adalah Allah menghapuskan tradisi jahiliyah yang dilakukan oleh orang-orang Arab. Tradisi jahiliyah telah menjadikan perempuan seperti barang yang dapat diwariskan apabila suaminya meninggal. Anak suami (bukan dari perempuan yang dicerai) atau kerabatnya, bahkan memiliki hak penuh atas perempuan yang ditinggal mati suaminya (Umar1999).

Dalam tradisi jahiliyah ada 4 macam perlakuan anak suami atau kerabatnya kepada perempuan yang ditinggal mati 
suaminya, yaitu: 1) Dinikahi tanpa mahar karena dia sudah dianggap seperti harta yang turun kepada ahli waris. 2) Dinikahkan dengan orang lain tapi maharnya diminta sebagai harta warisan. 3). Tidak diperbolehkan menikah sampai dia mau mengganti dengan harta warisan yang didapatkan dari bapaknya. 4) Tidak diperbolehkan menikah dengan siapa pun sampai mati lalu harta perempuan tersebut jadi milik mereka.

Perbuatan di atas tentu merupakan perbuatan kekerasan yang sangat jahat dan zhalim (Fisher 2001). Allah menurunkan ayat ini untuk menghapus tradisi yang penuh kekerasan tersebut. Islam datang membawa keadilan bagi manusia. Perempuan juga manusia seperti laki-laki. Tak sepantasnya laki-laki semena-mena terhadap perempuan. Orang yang mengaku beriman semestinya tidak akan mungkin melakukan kekerasan dan kezaliman seperti di atas (Umar 1999).

Mencermati produksi dari poster itu, tampak bahwa poster itu diproduksi oleh Pusat Studi Wanita (PSW) Universitas Islam Negeri Sunan Kalijaga bekerja sama dengan Ford Foundation. Tiga realitas itu, yaitu penggalan ayat, nama institusi pendidikan tinggi agama, Pusat Studi Wanita (PSW) Universitas Islam Negeri Sunan Kalijaga, dan funding agent (Ford Foundation), penting untuk ditampilkan ke dalam poster dengan pemaknaan bahwa selama ini teks agama dipandang sebagai sumber ketidakadilan dan ketidaksetaraan gender (Faqih 1996; Muhammad 1995; Abdullah, Arimbi 1998; Mulia 2001).

Munculnya nukilan ayat tersebut dengan tafsir yang baru menampakkan semangat penafsiran teks yang lebih berkesetaraan. Upaya yang dilakukan oleh Nazaruddin Umar (1999) yang membuat sebuah kajian tafsir tematik ayat-ayat yang bermuatan gender menunjukkan bahwa tafsir bukanlah sesuatu yang mutlak. Ridgeway (1999) menjelaskan bahwa keyakinan akan gender dapat berubah bersama waktu. Instiusi pendidkan tinggi Islam perlu ditampilkan untuk menunjukkan bahwa para intelektual menjadi motor bagi kehidupan yang adil. Dalam konteks Indonesia ini penting karena kampus dipandang sebagai wahana para cerdik pandai dan intelektual untuk perbaikan masyarakat. Selain itu, PSW sendiri merupakan sebuah entitas yang kiprahnya pun dalam upaya perjuangan ke arah keadilan dan kesetaraan gender telah diakui. Simbol Ford Foundation dapat dimaknai sebagai masyarakat internasional. Simbol ini menunjukkan betapa concern masyarakat internasional akan kehidupan yang berkeadilan dan berkesetaraan sangat tinggi. Dengan demikian dapat disimpulkan bahwa persoalan ketimpangan gender yang mengakibatkan kekerasan terhadap perempuan memang telah menjadi keprihatinan masyarakat dunia, sehingga semua lingkar komunitas, dengan 
level lokal, regional, dan internasional. Poster telah digunakan untuk menegaskan kembali bahwa agama memerintahkan agar perempuan dihormati dan dihargai. Penegasan akan perintah ini merupakan salah satu bentuk perlawanan diam-diam, yang nuansanya adalah sindiran bahwa agama menegaskan penghormatan terhadap perempuan, sehingga memunculkan pertanyaan mengapa dalam kenyataan perempuan tidak diperlakukan sebagaimana mestinya.

\section{Perlawanan dengan Ekspresi Teks Realitas Ketidakadilan Gender sebagai Akibat dari Interpretasi}

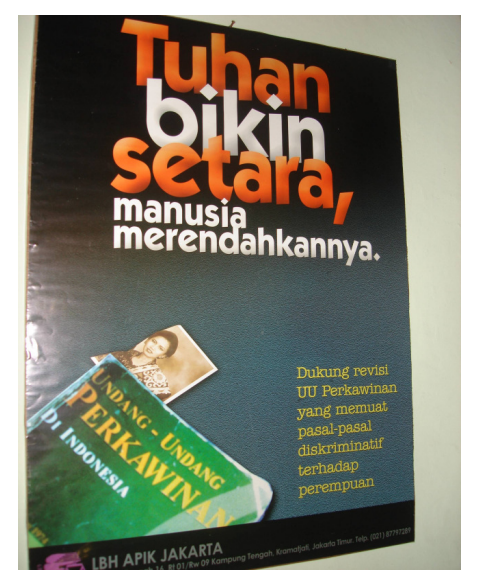

Gambar 2.

Gambar lain yang merupakan gambaran perlawanan terhadap ketidakadilan gender yang ada dalam masyarakat ditunjukkan dalam gambar 2. Dalam gambar 2 tampak perlawanan terhadap peraturan yang melibatkan negara. Teks yang tertulis secara eksplisit menyebutkan "Tuhan bikin setara, manusia merendahkannya"
Realitas lain yang ingin dinyatakan oleh Gambar 2 adalah bahwa negara pun sebenarnya ikut mendukung ketidakadilan gender melalui peraturannya. Gambar ini ingin menyatakan bahwa negara ikut melakukan ketidakadilan (Spencer 2007). Ini dimungkinkan terjadi karena negara tidak mempertimbangkan komunitas yang ada secara nyata (Scott 1998). Perspektif positifistik yang dipegang oleh negara menjadikan negara memandang seolah negara hanya dihuni oleh satu jenis kelamin, yaitu laki-laki. Pengetahuan mengenai keberadaan perempuan telah dikalahkan oleh adanya asumsi bahwa laki-laki memiliki posisi yang superior (lebih tinggi) dibanding perempuan (Fakih 1996). Pengabaian terhadap perempuan tersebut pada akhirnya mengakibatkan kebijakan yang diterbitkan oleh negara adalah kebijakan yang menyengsarakan perempuan (Shore dan Susan Wright 1997).

Produksi realitas kekerasan yang dilakukan oleh negara dimungkinkan karena ideologi patriarchi yang dianut oleh negara sehingga fungsi negara untuk mengamankan warga tidak berjalan (Spencer 2007). Dapat dilacak bagaimana fungsi pengamanan negara tidak berjalan. Setidaknya ada tiga level aktivitas negara yang mengakibatkan selalu tereproduksinya ketidakadilan dan kekerasan berbasis gender. Yang pertama adalah pemilihan pimpinan lembaga negara, pimpinan 
daerah, dan anggota legislatif yang masih didominasi oleh laki-laki. Upaya affirmative action untuk mendukung calon-calon perempuan untuk menduduki jabatan tersebut di atas masih mengalami banyak hambatan. Proses pemilihan yang ditetapkan oleh negara tampaknya tidak mampu mengalahkan image patriarchi yang hidup dalam masyarakat. Level aktivitas negara kedua yang mengakibatkan tereproduksinya kekerasan negara adalah sistem penetapan perundangan dan peraturan lain yang mengandalkan suara mayoritas. Dalam konteks seperti ini sudah pasti mayoritas akan dimenangkan oleh lakilaki. Dari sekian jumlah laki-laki yang menjadi menentu keputusan dalam forum penetapan peraturan itu tidak semuanya memiliki sensitifitas gender, yang mengakibatkan keputusan yang diambil juga tidak sensitif gender. Level aktivitas negara ketiga yang mereproduksi kekerasan adalah penentuan problem yang dibahas sebagai peraturan juga programatik berdasarkan prioritas. Dalam konteks ini prioritas dilihat dari perspektif mayoritas, yaitu laki-laki sehingga problem yang diangkat adalah problem yang hanya berkait dengan mayoritas, dan mengabaikan perempuan sebagai minoritas.

Poster di atas diproduksi oleh LBH APIK Jakarta, dan jika dilihat dari profile kelembagaannya, dapat dilihat secara jelas bahwa lembaga ini merupakan lembaga bantuan hukum yang bertujuan mewujud- kan masyarakat yang adil, makmur dan demokratis, serta menciptakan kondisi yang setara antara perempuan dan lakilaki dalam segala aspek kehidupan, baik politik, ekonomi, sosial maupun budaya (Profile Lembaga Bantuan Hukum APIK, 2015). Oleh karena itu poster di atas merupakan upaya dari lembaga bantuan hukum APIK untuk melakukan perlawanan dalam bentuk penyadaran bahwa negara pun dapat berbuat kekerasan berbasis gender.

Upaya perlawanan dalam bentuk penyadaran melalui poster dipandang cukup efektif karena poster dapat didistribusikan ke berbagai tempat, baik di ranah publik maupun privat, di lembaga formal maupun non-formal dan informal, sehingga dapat dibaca oleh berbagai kalangan sehingga dapat menimbulkan dampak terhadap pemahaman, sikap maupun prilaku pembaca. Punctum yang dimunculkan dalam poster berupa Undang-undang Perkawinan menunjukkan kekerasan negara juga dilakukan melalui institusi agama dengan ekspresi redaksional "Dukung revisi Undang-undang Perkawinan yang memuat pasal-pasal diskri-minatif terhadap perempuan". Implikasi dari perlawanan ini adalah bahwa negara pun memiliki andil dalam melakukan kekerasan terhadap perempuan karena undangundang itu dibentuk oleh institusi negara dan ditetapkan dengan proses yang ber- 
jenjang, dari perencanaan penetapam tentang tema aturan hingga penetapan perundang-undangan oleh lembaga legislatif. Realitas inilah yang dilawan oleh pembuat poster.

Adanya penanda LBH Apik dalam poster itu sangat kontekstual karena lembaga ini menangani berbagai kasus hukum yang terkait dengan ketidakadilan gender. Data dokumentasi LBH Apik telah berperan aktif dalam penanganan kasus-kasus ketidak adilan dan diskriminasi gender.

\section{Perlawanan dengan Ekspresi Teks yang Memuat Informasi bahwa Tindakan Kekerasan Berbasis Gender Memiliki Dampak Hukum}

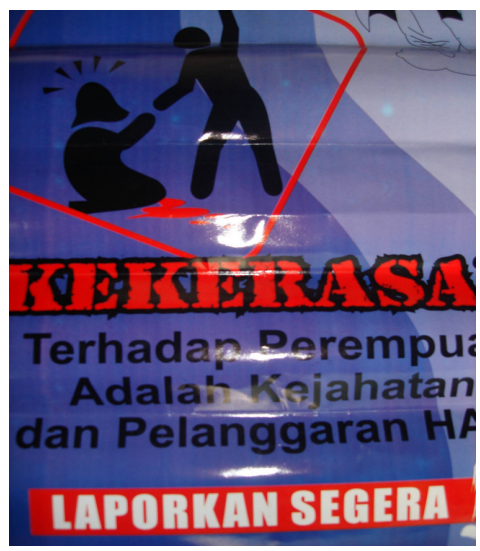

Gambar 3

Gambar 3 menunjukkan betapa perempuan sangat rentan terhadap kekerasan yang berbasis gender (Faqih 1996; Harsono 1997; Mosse 1993).

Dalam gambar tersebut ditunjukkan bahwa korban kekerasan adalah per- empuan, karena secara budaya umumnya perempuan yang mengalaminya. Angka kekerasan terhadap perempuan menegaskan realitas perempuan sebagai makhluk yang sangat rentan terhadap tindak kekerasan (Faqih 1996; Mosse 1993).

Realitas menunjukkan bahwa telah banyak perempuan yang masuk ke dunia publik (Ford 2008), namun pengalaman ini tidak serta merta menghilangkan fenomena kekerasan itu, apalagi ketika perempuan semata terdomestikasi (Roger 1989). Mengamati gambar ini, dengan posisi perempuan duduk dan laki-laki berdiri ingn menunjukkan relasi kuasa yang terbentuk di dalam masyarakat, yaitu posisi laki-laki yang berkuasa dan perempuan yang dikuasai. Ditangkap pula makna bahwa kekerasan yang terjadi dipandang wajar. Oleh karena itu perlu ditegaskan bahwa tindakan kekerasan terhadap perempuan melanggar hak asasi manusia. Dalam posisi semacam itu, Gambar 3 membuka kemungkinan negara untuk menolong kondisi tersebut, yaitu melalui prosedur peradilan. Dalam konteks ini seolah prosedur peradilan ditunjukkan sebagai jalan yang menjanjikan. Selain itu ada nuansa pembongkaran revolusioner dalam kata "Laporkan", karena secara budaya kekerasan dalam rumah tangga bersifat "privat" namun dengan kata itu ada upaya untuk membawa persoalan privat tersebut ke ke arena publik. Ini memunculkan makna bahwa 
upaya "baik-baik", antar personal tidak akan membuahkan hasil.

Melihat realitas perjuangan perempuan dalam mendapatkan keadilan gender, poster dapat dilihat sebagai upaya resistensi (Scott, 1990) perempuan menghadapi dominasi budaya patriarchi yang demikian kuat mendominasi kehidupan manusia.

\section{Kesimpulan}

Perjuangan untuk mencapai keadilan dan kesetaraan gender merupakan upaya kemanusiaan karena berkait dengan hak asasi manusia. Gambaran yang ditampakkan dalam poster-poster di atas menunjukkan bahwa ketimpangan gender terjadi sedemikian rupa berangkai dari level nilai hingga praktis. Dalam kondisi ketimpangan gender, muncul perlawanan yang terekspresi dalam bentuk poster. Dari kajian di atas dapat disimpulkan bahwa perlawanan atas ketimpangan gender muncul dalam tiga bentuk:

Pertama, perlawanan dengan penegasan tentang kewajiban berbuat baik kepada perempuan. Perlawanan dengan teks yang memuat penegasan mengenai kewajiban untuk berbuat baik kepada perempuan dikatakan sebagai teks perlawanan karena mengandung sindiran bahwa agama sebenarnya memerintahkan laki-laki untuk berbuat baik terhadap perempuan, namun demikian fenomena kekerasan terhadap perempuan menjadi gejala yang meluas.
Kedua, perlawanan dengan ekspresi teks bahwa ketidakadilan gender muncul akibat interpretasi agama Terungkap dari kajian ini bahwa ekspresi visual poster yang meneguhkan agar laki-laki dan perempuan saling menghormati, merupakan resistensi terhadap interpretasi teks yang memperlakukan laki-laki dan perempuan secara tidak adil. Selain itu resistensi juga dilakukan oleh negara melalui peraturan yang diteguhkan oleh perundangan, dan individu ikut berperan karena proses pembelajaran budaya yang menyebabkan tentang tindak kekerasan terhadap perempuan bukan masalah dalam kehidupan. Semestinya negara dapat mengawal proses pencapaian keadilan gender melalui berbagai produk perundangan yang dihasilkan

Ketiga, perlawanan dengen ekspresi teks bahwa tindakan kekerasan berbasis gender memiliki dampak hukum. Bermula dari interpreasi teks yang tidak adil pada akhirnya memunculkan praktek yang tidak adil pula. Bersama dengan waktu dan perjuangan praktek ketidakadilan dan kekerasan juga memiliki dampak hukum. Oleh karena itu bentuk perlawanan ketiga ini mengingatkan para pelaku kekerasan untuk mengetahui dampak hukum dari perilaku kekerasannya. Demikian pula bagi masyarakat semestinya mengetahui adanya payung hukum untuk menindak para pelaku kekerasan 
Kondisi ideal yang diinginkan masih merupakan upaya, dan dalam proses pencapaian itu, perempuan sebagai pihak yang "subordinated" tetap dalam posisi yang sama, Dalam konteks inilah dapat dipahami bahwa perjuangan dan perlawanan dari pihak yang "subordinated itu terus berlangsung.]

\section{Daftar Pustaka}

Abdullah, Irwan. 1997. "Dari Domestik ke Publik: Jalan Panjang Pencarian Identitas Perempuan" dalam Sangkan Paran Gender. Yogyakarta: Pustaka Pelajar.

1998. "Perempuan Fantastis, Negara dan Tubuh ("Bukan Lelaki") Modern" dalam Perempuan dan Politik Tubuh Fantastis. Yogyakarta, Kanisius.

_-_. 2001. Seks, Gender, \& Reproduksi Kekuasaan. Yogyakarta: Tarawang Press.

Appadurai, Arjun. 2005. Modernity at Large: Cultural Dimension of Globalization, Minnesota: University of Minnesota Press

Arimbi et al., 1998. "Mitos Peran "Bukan Laki-laki” Masak, Macak, Manak: Dikaji Ulang..." dalam Perempuan dan Politik Tubuh Fantastis. Yogyakarta: Kanisius.

Barthes, Roland. 1981. Camera Lucida. New York: Hill and Wang.

Blasco, Paloma Gayy dan Huon Wardle, 2007. How to Read Ethnography. London: Routledge.
Budiman, Kris. 1992. "Subordinasi Perempuan dalam Bahasa Indonesia" dalam Budi Susanto et al. (ed.). Citra wanita dan Kekuasaan (Jawa). Yogyakarta: Kanisius.

Certeau, Michel de. 1984. The Practice of Everyday Life. Berkeley: University of California Press.

Errington, Shelly, 1990. "Recasting Sex, Gender, and Power: A Theoretical and Regional Overview" dalam Power and Difference: Gender in Island Southeast Asia. Stanford, California, Stanford University Press.

Faqih, Mansur. 1996. Gender dan Transformasi Sosial, Yogyakarta: Pustaka Pelajar

Featherstone, Mike. 2001. Postmodernisme dan Budaya Konsumen (terj. Misbah Zulfa Elizabeth), Yogyakarta: Pustaka Pelajar.

Ford, Michele dan Lyn Parker, ed. 2008. Women and Work in Indonesia. New York: Routledge.

Harsono, Rebeka. 1997. "Gerakan Perempuan: Antara Kepentingan Perempuan dan Politik Gender," dalam Irwan Abdullah ed. Sangkan Paran Gender, Yogyakarta: Pustaka Pelajar.

Hine, Christine. 2000. Virtual Ethnography, London: Sage Publication.

Howells, Richard. 2004. Visual Culture. Malden: Blackwell Publishers, Ltd.

Ihromi, T0, 1999. "Paradigma Baru bagi Pengkajian Masalah Wanita dan Jender dalam Antropologi." Antropologi Indonesia, Th. XXIII, No. 60. 
Irianto, Sulistyowati. 2004. "Keadilan Sosial, Apakah Juga Ditujukan bagi Perempuan?" dalam Keadilan Sosial: Upaya Mencari Makna Kesejahteraan Bersama di Indonesia. Jakarta: Penerbit Buku Kompas.

Laksono, P. M. 2004. "Mediasi-mediasi Visual Sebelum dan Sesudah Reformasi di Indonesia: Sebuah Pencarian Keadilan Sosial" dalam Keadilan Sosial: Upaya Mencari Makna Kesejahteraan Bersama di Indonesia. Jakarta: Penerbit Buku Kompas.

Legowo, TA. 2004. "Negara, Politik, dan Keadilan Sosial" dalam Keadilan Sosial: Upaya Mencari Makna Kesejahteraan Bersama di Indonesia, Jakarta: Penerbit Buku Kompas.

Mosse, Julia Cleves. 1993. Gender dan Pembangunan. Yogyakarta: Pustaka Pelajar.

Mrazek, Rudolf. 2006. Enginers of Happy Land: Perkembangan Teknologi dan Nasionalisme di Sebuah Koloni. Jakarta: Buku Obor.

Mulia, Musdah. 2001. "Membangun Kemandirian Perempuan: Perspektif Agama" makalah disampaikan dalam Seminar Sehari Membangun Kemandirian Perempuan yang diselenggarakan oleh PW Fatayat Jawa Temngah bekerjasama dengan Tim Penggerak PKK Propinsi Jawa Tengah di Semarang, 22 April 2001.

Odih, Pamela. 2007. Advertising in Modern and Postmodern Times. London: Sage Publication Ltd.

Pratiwi. 1998. "Makanan (Tradisional) Modern dan Tubuh Industrif Perempuan" dalam Perempuan dan Politik Tubuh Fantastis. Yogyakarta: Kanisius.

Rahardjo, Dawam. 2000. "Masyarakat Madani" dalam Bahan Bacaan Loka Karya Islam dan Pemberdayaan Civil Society di Indonesia yang dilaksanakan oleh Walisongo Research Institute (WRI) IAIN Walisongo bekerjasama dengan Pusat Pengkajian Islam dan Masyarakat (PPIM) IAIN Jakarta dan Ford Foundation,13-14 Juni 2000 di Semarang.

Ratih, In Bene. 2005. "Perempuan dan Teater" dalam Teori-teori Kebudayaan, Mudji Sutrisno dan Hendar Putranto ed. Yogyakarta: Penerbit Kanisius.

Regev, Nathansohn. 2007. "Ways Of SocioVisualizing" dalam Visual Studies 22 (1). April 2007.

Rogers, Barbara. 1980. The Domestication of Women: Discrimination in Developing Societies. London dan New York: Tavistock Publication.

Rose, Gillian. 2007. Visual Methodologies: An Introduction to the Interpretation of Visual Materials. London: Sage Publications.

Scott, James C. 1990. Domination and Arts of Resistance. New Heaven: Yale University.

Scott, James C. 1998. Seeing Like a State: How Certain Schemes to Improve the Human Condition Have Failed. New Heaven dan London: Yale University Press.

Shore, Cris dan Susan Wright, ed. 1997. Anthropology of Policy: Critical Perspectives on Governance and Power, London dan New York: Routledge. 
Sontag, Susan. 1990. Against Interpretation. New York: Anchor Books Doubleday.

Spencer, Jonathan. 2007. Anthropology, Politics, and the State. Cambridge: Cambridge University Press.

Susanto, Budi S. J. 1993. Peristiwa Yogya 1992: Siasat Politik Massa Rakyat Kota. Yogyakarta: Penerbit Kanisius.

2008. Membaca Postkolonialitas Indonesia. Yogyakarta: Penerbit Kanisius.
Umar, Nasaruddin. 1999. Argumen Kesetaraan Gender: Perspektif Al-Qur'an. Jakarta: Paramadina.

Vangeliti, Anita L. Harry T. Reis, dan Mary Anne Fitzpatrick, eds. 2002. Stability and Change in Relationship. Cambridge: Cambridge University Press

Walker, John A. dan Sarah Chaplin. 1997. Visual Culture: An Introduction, Manchester: Manchester University Press. 


\section{Author Guidelines}

\section{A. Persyaratan Umum}

1. Naskah merupakan hasil penelitian sosial keagamaan dan modernitas yang sudah diformat sesuai pola penulisan artikel jurnal ilmiah.

2. Naskah diutamakan ditulis dalam Bahasa Inggris.

3. Naskah merupakan karya orisinil (bukan plagiasi) dan belum pernah dimuat di jurnal atau media cetak/online lainnya.

4. Naskah dikirim ke Redaksi JSW: Jurnal Sosiologi Walisongo melalui submission Open Journal Systems (OJS) pada http://journal.walisongo.ac.id/index.php/jsw

5. Naskah diketik menggunakan Microsoft Word format RTF, font Times New Roman, size 12 pt, 1,5 spasi, ukuran halaman A4, dengan panjang tulisan 20-25 halaman (sekitar 5.000 - 7.000 kata).

6. Untuk menperoleh keterangan lebih lanjut, silakan menghubungi redaksi melalui email: jurnal.sosiologi@walisongo.ac.idatau menghubungi kantor redaksi (024) 76435986.

\section{B. Persyaratan Khusus}

1. Naskah merupakan hasil penelitian dalam bidang sosial keagamaan dan modernitas.

2. Naskah tidak mencantumkan nama penulis, instansi, dan alamat email. Nama penulis, instansi, dan alamat email dicantumkan saat melakukan registrasi OJS dan pengisian metadata naskah.

3. Naskah memuat:

a. Judul, dengan ketentuan:

- Judul merupakan rumusan pokok bahasan yang singkat, padat, dan jelas.

- Dalam judul sudah tercantum variabel-variabel utama penelitian.

- Judul diketik dengan hurup kapital tebal (capital, bold).

b. Abstrak, dengan ketentuan:

- Abstrak ditulis dalam bahasa Inggris dan bahasa Indonesia. 
- Abstrak merupakan intisari dari pokok bahasan naskah.

- Abstrak ditulis dalam satu paragraf berjarak satu spasi, dengan panjang 100250 kata.

- Abstrak disajikan secara singkat dan jelas, dengan memuat empa. argumentasi logis, perlunya dilakukan penelitian untuk memecahkan masalah, pendekatan yang digunakan (metode), hasil yang dicapai, serta simpulan yang diperoleh (IMRAD: introduction, methods, results, analysis and discussions).

c. Kata Kunci (keywords) maksimal 5 (lima) kata.

d. Isi naskah, dengan sistematika sebagai berikut:

- Pendahuluan yang meliputi latar belakang masalah, perumusan masalah, tujuan dan manfaat penelitian, serta metodologi yang digunakan (IMRAD: introduction, methods, results, analysis and discussions).

- Review pustaka yang berisi kajian teoretik dan hasil penelitian terdahulu yang relevan.

- Hasil dan pembahasan.

- Simpulan dan rekomendasi.

- Daftar pustaka.

4. Rujukan menggunakan ASA (American Sociological Association).[] 


\section{ACKNOWLEDGEMENTS}

The members of the editorial team of JSW: Jurnal Sosiologi Walisongo extend the gratitude to all the reviewers who have contributed to the peer review process of the manuscripts in Vol 1, No 2 (2017). Professional support and assistance from all respected reviewers have made this journal qualified to be published:

1. Abu Rokhmad, Universitas Islam Negeri Walisongo, Semarang

2. Agus Nurhadi, Universitas Islam Negeri Walisongo, Semarang

3. Misbah Zulfa Elizabeth, Universitas Islam Negeri Walisongo, Semarang

4. Muhyar Fananai, Universitas Islam Negeri Walisongo, Semarang

5. Najahan Musyafak, Universitas Islam Negeri Walisongo, Semarang

6. Thohir Yuli Kusmanto, Universitas Islam Negeri Walisongo, Semarang

7. TriMarhaeni Pudji Astuti, Universitas Negeri Semarang 


\section{\begin{tabular}{l|l} 
JW & $\begin{array}{l}\text { JURNAL } \\
\text { SOSIOLOGI } \\
\text { WALISONGO }\end{array}$
\end{tabular}}

JSW: Jurnal Sosiologi Walisongo - ISSN 2503-3166 (print) ISSN 2503-3182 (online) is a critical, reflective, and transformative academic media that is published by Laboratorium Sosiologi, Fakultas IImu Sosial dan IImu Politik, Universitas Islam Negeri Walisongo Semarang, in the effort for developing the discipline of Sociology having the perspective of unity of sciences. Article is based on research in all division of sociology like sociology of religion, sociology of politic, sociology of law, sociology of development, urban/rural sociology, democracy, social ethic, anthropology, community development, social philosophy, gender, and social welfare. 